\title{
PENGARUH REBUSAN DAUN ALPUKAT (Folium Perseae) TERHADAP PENURUNAN KADAR ASAM URAT DARAH PADA PENDERITA GOUT DI KLINIK PRATAMA BAROKAH KABUPATEN SUMENEP
}

\author{
Zakiyah Yasin ${ }^{1}$, Imam Muslim ${ }^{2}$, Nisa Tamama ${ }^{3}$ \\ Fakultas Ilmu Kesehatan Universitas Wiraraja ${ }^{1,2,3}$ \\ Email : zakiyahfik@wiraraja.ac.id
}

\begin{abstract}
Gout or hyperuricemia or elevated blood uric acid is one of several very dangerous diseases and the symptoms of increased uric acid in the blood not only seriously impair health but can result in physical defects. One of nonfarmakologi management is by avocado leaf stew.

The purpose of this study was to determine whether there is the influence of avocado leaves (folium perseae) to the decrease in blood uric acid levels in people with gout in Clinic Pratama Barokah Sumenep regency.

This research uses quantitative approach, research method used is experimental with quasi-experiment research design (quasy-experiment). Population of 50 people. Sampling technique using Purposive sampling, sample of 10 people who visited in February. The data collection tool is an observation sheet, GCU 3 in one. Analysis using paired sample T test.

The results showed that there was influence of avocado leaf stool (folium perseae) to the decrease of blood uric acid level in gout patient in Pratama Barokah Clinic of Sumenep Regency with p value $=0,00$, because $p$ value $<0,05$. It is expected from the results of this study avocado leaf stew can be one non-pharmacological therapy to handle gout.
\end{abstract}

Keywords: Avocado leaves (folium perseae), Gout

\section{PENDAHULUAN}

Gout atau hiperurisemia atau peningkatan asam urat darah merupakan salah satu dari beberapa penyakit yang sangat membahayakan dan gejala dari peningkatan asam urat dalam darah bukan hanya mengganggu kesehatan serius tetapi dapat mengakibatkan cacat pada fisik (Pribadi \& Ernawati, 2010).

Tubuh memproduksi asam urat darah sekitar $80-85 \%$, sedangkan sisanya berasal dari sumber makanan yang mengandung purin. Kadar asam urat normal wanita dewasa 2,4-5,7 mg/dL; pria dewasa 3,4-7,0 mg/dL; dan anak-anak 2,8-4,0 $\mathrm{mg} / \mathrm{dL}$, hal ini dapat menjadi patokan bagi masyarakat sebagai ukuran normal asam urat darah pada tubuh kita sendiri jika kita periksa asam urat (Lingga, 2012).

Menurut catatan WHO bahwa penderita gangguan sendi di Indonesia mencapai $81 \%$ dari total populasi, dari jumlah tersebut hanya $29 \%$ yang pergi ke dokter, sedangkan $71 \%$ cenderung langsung mengkonsumsi obat-obatan pereda 
nyeri yang dijual bebas (skripsi doni kuswandono, 2013). Dari Prevalensi hiperurisemia di Desa Tenganan Pegrisingan Karangasem, Bali pada tahun 2011 didapatkan sebesar 28\%. Minahasa, Sulawesi Utara, didapatkan prevalensi hiperurisemia pada tahun 1999 sebesar $34,30 \%$ pada pria dan $23,31 \%$ pada wanita usia dewasa muda. Pada tahun 2003 didapatkan angka kejadian artritis gout di Minahasa yang cukup tinggi yaitu sebesar 29,2\% (Purwanto, 2011).

Data yang diperoleh di PoKesDes Desa Bunder Barat Kecamatan Pademawu tahun 2015 dari keseluruhan yang menderita penyakit gout dari keseluruhan sebanyak 172 orang, sedangkan yang datang untuk periksa sebanyak 54 orang dengan persentase $(28,1 \%)$, pada tahun 2016 dari keseluruhan yang menderita gout sebanyak 192 orang, sedangkan yang datang untuk periksa di PosKesDes Desa Bunder Barat sebanyak 62 dengan persentase (36\%), dan sisanya masih belum memeriksakan diri. Perevalensi penderita gout dari tahun ketahun semakin meningkat jumlah penderitanya (Amrullah, 2016).

Peneliti telah melakukan percobaan awal kepada salah satu klien sebelum diberikan perlakuan klien dicek dulu kadar asam urat darah, didapatkan hasil asam urat yaitu 8,6 setelah itu diberikan rebusan daun alpukat selama 2 hari sesuai dengan standar oprasional prosedur, kemudian dicek kembali setelah perlakuan dan didapatkan kadar asam urat dalam darah menurun menjadi 8,4 mg/dl.

Asam urat sebenarnya berjasa dalam tubuh, salah satu fungsinya asam urat adalah antioksidan alami yang dihasilkan sendiri oleh tubuh (antioksidan endogen), dalam kadar yang normal, asam urat berperan sebagai antioksidan yang penting dalam plasma. Sekitar $60 \%$ radikal bebas yang ada dalam serum manusia "Dibersihkan" oleh asam urat. Asam urat bersifat larut dalam darah sehingga mampu menangkap radikal bebas dan melakukan chelasi terhadap logam transisi yang bersifat merusak keutuhan sel dalam tubuh (Lingga, 2012).

Fungsi penting asam urat lenyap saat kadar asam urat berada diatas ambang batas normal. Jika kadarnya tinggi, asam urat justru berubah menjadi radikal bebas yang akan merusak keutuhan sel (Lingga, 2012).

Berdasarkan uraian latar belakang di atas maka penulis tertarik melakukan penelitian pengaruh rebusan daun alpukat (folium perseae) terhadap penurunan kadar asam urat darah pada penderita gout di Klinik Pratama Barokah Kecamatan Ambunten Kabupaten Sumenep. Hal ini perlu karena jika kadar asam urat dalam darah terus meningkat maka akan menyebabkan komplikasi gagal ginjal kronis, penyakit mata, dan penyakit jantung pada penderita.

\section{METODE PENELITIAN}

Metode dalam penelitian ini menggunakan Quasy-experiment, peneliti membuat dua kelompok, kelompok pertama kelompok perlakuan (K-A) dan kelompok kedua kelompok kontrol (K-B). K-A dan K-B dilakukan pemeriksaan kadar asam urat darah sebelum diberikan minuman dari rebusan daun alpukat, 
kemudian K-A diberikan perlakuan dengan meminum air dari hasil rebusan daun alpukat, dan pada K-B tidak di berikan perlakuan. Setelah 7 hari, K-A dan K-B dilakukan pemeriksaan kadar asam urat darah menggunakan alat ukur Easy Touch GCU 3 in 1.

Penulis menggunakan teknik purposife sampling yaitu teknik penentuan sampel dengan pertimbangan tertentu sesuai yang dikehendaki peneliti.

\section{HASIL DAN PEMBAHASAN}

Tabel 1 Distribusi Frekuensi Responden Penderita Gout Berdasarkan Umur di Klinik Pratam Barokah Kabupaten Sumenep 2018

\begin{tabular}{lcccc}
\hline Karakteristik & K. Kontrol & $\%$ & K. Perlakuan & \multirow{2}{*}{$\%$} \\
& F & & F & \\
\hline Umur & & & & \\
Dewasa akhir (36-45) & 1 & 20 & 0 & 0 \\
Lansia Awal (46-55) & 3 & 60 & 3 & 60 \\
lansia Akhir (56-65) & 1 & 20 & 2 & 40 \\
\hline \multicolumn{1}{c}{ TOTAL } & 5 & 100,0 & 5 & 100,0 \\
\hline
\end{tabular}

Sumber: Data Primer 2018

Tabel 2 Distribusi Frekuensi Responden pada Penderita Gout Berdasarkan Jenis Kelamin di Klinik Pratama Barokah Kabupaten Sumenep 2018

\begin{tabular}{lcccc}
\hline Karakteristik & K. Kontrol & $\%$ & K. Perlakuan & $\%$ \\
& F & & F & \\
\hline Jenis Kelamin & & & & 40 \\
Laki-laki & 3 & 60 & 2 & 60 \\
Perempuan & 2 & 40 & 3 & 100,0 \\
\hline TOTAL & 5 & 100,0 & 5 &
\end{tabular}

Sumber: Data Primer 2018

Tabel 3 Distribusi Frekuensi Kadar Asam Urat Darah Sebelum Perlakuan Pada Penderita Gout Kelompok Kontrol dan Kelompok Perlakuan di Klinik Pratama Barokah Kabupaten Sumenep Tahun 2018

\begin{tabular}{ccccccc}
\hline & \multicolumn{2}{c}{ Kelompok Kontrol } & \multicolumn{3}{c}{ Kelompok Perlakuan } \\
\cline { 2 - 7 } No & $\begin{array}{c}\text { GCU } \\
(\mathrm{mg} / \mathrm{dl})\end{array}$ & $\mathrm{F}$ & $\%$ & $\begin{array}{c}\text { GCU } \\
(\mathrm{mg} / \mathrm{dl})\end{array}$ & $\mathrm{F}$ & $\%$ \\
\hline 01 & 6,6 & 1 & 20 & 7,7 & 1 & 20 \\
02 & 8,3 & 1 & 20 & 8,0 & 1 & 20 \\
03 & 7,7 & 1 & 20 & 6,7 & 1 & 20 \\
04 & 11,2 & 1 & 20 & 7,9 & 1 & 20 \\
05 & 8,9 & 1 & 20 & 7,2 & 1 & 20 \\
\hline \multicolumn{2}{r}{ TOTAL } & 5 & 100,0 & & 5 & 100,0 \\
\hline
\end{tabular}

Sumber: Data Primer 
Tabel 4 Distribusi Frekuensi Kadar Asam Urat Darah Sesudah Perlakuan Pada Kelompok Kontrol dan Kelompok Perlakuan di Klinik Pratama Barokah Kabupaten Sumenep Tahun 2018

\begin{tabular}{ccccccc}
\hline & \multicolumn{3}{c}{ Kelompok Kontrol } & \multicolumn{3}{c}{ Kelompok Perlakuan } \\
\cline { 2 - 7 } No & $\begin{array}{c}\text { GCU } \\
(\mathrm{mg} / \mathrm{dl})\end{array}$ & $\mathrm{F}$ & $\%$ & $\begin{array}{c}\text { GCU } \\
(\mathrm{mg} / \mathrm{dl})\end{array}$ & $\mathrm{F}$ & $\%$ \\
\hline 01 & 6,8 & 1 & 20 & 6,6 & 1 & 20 \\
02 & 9,0 & 1 & 20 & 7,1 & 1 & 20 \\
03 & 7,3 & 1 & 20 & 5,8 & 1 & 20 \\
04 & 10,9 & 1 & 20 & 6,7 & 1 & 20 \\
05 & 9,1 & 1 & 20 & 6,3 & 1 & 20 \\
\hline \multicolumn{2}{l}{ TOTAL } & 5 & 100,0 & & 5 & 100,0 \\
\hline
\end{tabular}

Sumber: Data Primer

Tabel 5 Hasil Uji T sampel berpasangan pada kelompok kontrol sebelum dan sesudah

\begin{tabular}{ccccccc}
\hline \multirow{2}{*}{ No } & \multicolumn{3}{c}{ Sebelum } & \multicolumn{3}{c}{ Sesudah } \\
\cline { 2 - 7 } & $\begin{array}{c}\text { GCU } \\
(\mathrm{mg} / \mathrm{dl})\end{array}$ & $\mathrm{F}$ & $\%$ & $\begin{array}{c}\text { GCU } \\
(\mathrm{mg} / \mathrm{dl})\end{array}$ & $\mathrm{F}$ & $\%$ \\
\hline 01 & 6,6 & 1 & 20 & 6,8 & 1 & 20 \\
02 & 8,3 & 1 & 20 & 9,0 & 1 & 20 \\
03 & 7,7 & 1 & 20 & 7,3 & 1 & 20 \\
\hline 04 & 11,2 & 1 & 20 & 10,9 & 1 & 20 \\
05 & 8,9 & 1 & 20 & 9,1 & 1 & 20 \\
\hline & TOTAL & 5 & 100,0 & & 5 & 100,0 \\
\hline
\end{tabular}

Sumber: Data Primer 2018

Tabel 6 Hasil Uji T sampel berpasangan pada kelompok Perlakuan sebelum dan sesudah perlakuan.

\begin{tabular}{ccccccc}
\hline & \multicolumn{2}{c}{ Sebelum Perlakuan } & \multicolumn{3}{c}{ Sesudah Perlakuan } \\
\cline { 2 - 7 } No & $\begin{array}{c}\text { GCU } \\
(\mathrm{mg} / \mathrm{dl})\end{array}$ & $\mathrm{F}$ & $\%$ & $\begin{array}{c}\text { GCU } \\
(\mathrm{mg} / \mathrm{dl})\end{array}$ & $\mathrm{F}$ & $\%$ \\
\hline 01 & 7,7 & 1 & 20 & 6,6 & 1 & 20 \\
02 & 8,0 & 1 & 20 & 7,1 & 1 & 20 \\
03 & 6,7 & 1 & 20 & 5,8 & 1 & 20 \\
04 & 7,9 & 1 & 20 & 6,7 & 1 & 20 \\
05 & 7,2 & 1 & 20 & 6,3 & 1 & 20 \\
\hline & TOTAL & 5 & 100,0 & & 5 & 100,0 \\
\hline
\end{tabular}

Sumber: Data Primer 2018 
Tabel 7 Hasil Uji T sampel tidak berpasangan pada kelompok perlakuan sesudah dan kelompok kontol sesudah.

\begin{tabular}{ccccccc}
\hline & \multicolumn{3}{c}{ Kelompok Kontrol } & \multicolumn{3}{c}{ Kelompok Perlakuan } \\
\cline { 2 - 7 } No & $\begin{array}{c}\text { GCU } \\
(\mathrm{mg} / \mathrm{dl})\end{array}$ & $\mathrm{F}$ & $\%$ & $\begin{array}{c}\text { GCU } \\
(\mathrm{mg} / \mathrm{dl})\end{array}$ & $\mathrm{F}$ & $\%$ \\
\hline 01 & 6,8 & 1 & 20 & 6,6 & 1 & 20 \\
02 & 9,0 & 1 & 20 & 7,1 & 1 & 20 \\
03 & 7,3 & 1 & 20 & 5,8 & 1 & 20 \\
04 & 10,9 & 1 & 20 & 6,7 & 1 & 20 \\
05 & 9,1 & 1 & 20 & 6,3 & 1 & 20 \\
\hline \multicolumn{2}{c}{ TOTAL } & 5 & 100,0 & & 5 & 100,0 \\
\hline
\end{tabular}

Sumber: Data Primer 2018

Hasil penelitian ini menunjukkan nilai kadar asam urat darah sebelum perlakuan (pretest) pemberian rebusan daun alpukat yaitu tertinggi pada kelompok kontrol adalah 11,2 mg/dl dan pada kelompok perlakuan $8.0 \mathrm{mg} / \mathrm{dl}$ dan untuk nilai terendahnya sebelum diberikan perlakuan pada kelompok kontrol nilainya 6,6 $\mathrm{mg} / \mathrm{dl}$ dan pada kelompok perlakuan nilai $6,7 \mathrm{mg} / \mathrm{dl}$ dengan nilai rata-rata kelompok kontrol 8,54 mg/dl dan kelompok perlakuan 7,5 mg/dl.

Berdasarkan umur responden penderita gout di Klinik Pratama Barokah Kabupaten Sumenep tahun 2018 pada kelompok kontrol > setengahnya berada pada lansia awal (46-55) tahun dengan jumlah responden sebanyak 3 orang (60\%) sedangkan kelompok perlakuan juga sama berada pada lansia awal (46-55) dengan jumlah responden sebanyak 3 orang $(60 \%)$.

Usia yang sudah lebih dari 40 tahun akan rentang terkena penyakit, termasuk peningkatan kadar asam urat dalam darah. Asam urat merupakan penyakit yang sering ditemui pada laki - laki. Hal ini sejalan dengan penelitian yang pernah dilakukan oleh Cumayunaro tahun 2017 mengatakan bahwa laki - laki memiliki hormone esktrogen lebih sedikit dari pada wanita.

Kadar asam urat dalam darah yang tinggi akan mengakibatkan penyakit lain seperti penyakit jantung, batu ginjal dan penyakit lainnya. maka peneliti memberikan rebusan daun alpukat untuk dapat menurunkan kadar asam urat dalam darah pada penderita Gout.

Hasil penelitian ini menunjukkan nilai kadar asam urat darah sesudah perlakuan (posttest) pemberian rebusan daun alpukat yaitu tertinggi pada kelompok kontrol adalah 10,9 mg/dl dan pada kelompok perlakuan 7,1 mg/dl dan untuk nilai terendahnya sebelum diberikan perlakuan pada kelompok kontrol nilainya 6,8 $\mathrm{mg} / \mathrm{dl}$ dan pada kelompok perlakuan nilai $6,3 \mathrm{mg} / \mathrm{dl}$ dengan nilai rata-rata pada kelompok kontrol 8,62 mg/dl dan kelompok perlakuan 6,5 mg/dl.

Penurunan kadar asam sesudah pemberian air rebusan daun alpukat dipengaruhi oleh kandungan flavonoid yang bersifat antioksidan yang dapat menghambat sintesis xanthin oxidase, sehingga pembentukan asam urat dalam 
tubuh terhambat serta dipengaruhi juga oleh kandungan tritepen, polyphenol dan alkaloid yang bersifat diuretik yang memproduksi urin lebih banyak sehingga asam urat keluar melalui urin (Suparni \& Wulandari, 2013).

Penyakit degenaratif ini dapat diredam, bila tubuh memiliki penangkap radikal bebas. Aktivitas penangkapan radikal bebas dari daun alpukat sangat berpotensi sebagai antioksidan, antibakteri dan melancarkan air seni, dapat mengobati batu ginjal, mengobati sakit perut, sakit pinggang, asam urat dan hipertensi (Andareto, 2015).

Peningkatan asam urat dapat dicegah dengan kita menjaga pola makan dan hidup agar kita terhindar dari penyakit gout, dan untuk pengobatan jika masih memungkinkan atau gout akut bisa kita menggunakan obat alternative menggunakan obat tradisional karena sedikitnya efek samping yang timbul untuk tubuh kita karena terbuat dari bahan yang alami, dan juga terbilang murah.

Pada uji Tests of Normality Kolmogorov_Smirnou karena jumlah sampel <50 maka hasil yang di baca yaitu pada sahpiro wilk kadar asam urat pada kelompok kontrol sebelum dan sesudah nilai $\mathrm{p}=0,772$ sebelum, $\mathrm{p}=0661$ sesudah karena nilai $\mathrm{p}>0,05$, dapat diambil kesimpulan bahwa distribusi skor kadar asam urat darah kelompok kontrol pada penderita gout sebelum dan sesudah berdistribusi normal, menggunakan Uji T sampel berpasangan.

Hasil Uji $\mathrm{T}$ berpasangan pada kelompok kontrol sebelum dan sesudah terhadap penurunan kadar asam urat darah pada penderita gout di Klinik Pratama Barokah Kabupaten Sumenep didaptkan nilai $\mathrm{p}=0,708$, karena nilai $\mathrm{p}>0,05$, dapat diambil kesimpulan tidak ada pengaruh terhadap penurunan kadar asam urat darah pada penderita gout di Klinik Pratama Barokah Kabupaten Sumenep.

Pada uji Tests of Normality Kolmogorov_Smirnou karena jumlah sampel $<50$ maka hasil yang di baca yaitu pada sahpiro wilk kadar asam urat pada kelompok perlakuan sebelum dan sesudah nilai $\mathrm{p}=0,434$ sebelum, $\mathrm{p}=0943$ sesudah karena nilai $\mathrm{p}>0,05$, dapat diambil kesimpulan bahwa distribusi skor kadar asam urat darah kelompok perlakuan pada penderita gout sebelum dan sesudah berdistribusi normal, menggunakan Uji T sampel berpasangan.

Hasil Uji T berpasangan pada kelompok perlakuan sebelum dan sesudah perlakuan terhadap penurunan kadar asam urat darah pada penderita gout di Klinik Pratama Barokah Kabupaten Sumenep didaptkan nilai $\mathrm{p}=0,000$, karena nilai $\mathrm{p}<$ 0,05, dapat diambil kesimpulan ada pengaruh rebusan daun alpukat terhadap penurunan kadar asam urat darah pada penderita gout di Klinik Pratama Barokah Kabupaten Sumenep.

Pada uji Tests of Normality Kolmogorov_Smirnou karena jumlah sampel $<50$ maka hasil yang di baca yaitu pada sahpiro wilk kadar asam urat sebelum pada kelompok kontrol (tidak diberikan rebusan daun alpukat) mempunyai nilai $\mathrm{p}=0,661$ dan kelompok perlakuan ( diberikan rebusan daun alpukat) $p=0,943$, karena nilai p>0,05, dapat diambil kesimpulan bahwa distribusi skor asam urat sesudah baik 
yang tidak diberikan rebusan daun alpukat maupun yang diberikan rebusan daun alpukat berdistribusi normal, menggunakan Uji T sampel tidak berpasangan.

Hasil Uji T tidak berpasangan (bebas) pada kelompok kontrol dan kelompok perlakuan sesudah terhadap penurunan kadar asam urat darah pada penderita gout di Klinik Pratama Barokah Kabupaten Sumenep didapatkan nilai $\mathrm{p}=0,041$, karena nilai $\mathrm{p}<0,05$, dapat diambil kesimpulan adanya perbedaan bermakna antara kelompok kontrol sesudah dan kelompok perlakuan sesudah diberikan rebusan daun alpukat.

Hasil penelitian ini didukung penelitian yang dilakukan Cumayunaro (2017) dapat disimpulkan ada pengaruh pemberian rebusan daun salam terhadap kadar asam urat pada pasien dengan gout di Puskesmas Andalas Padang dengan pemberian 2 kali sehari selama 7 hari. Dipengaruhi oleh kandungan flavonoid yang bersifat antioksidan.

Penggunaan terapi non farmakologi untuk menurunkan kadar asam urat membutuhkan yang waktu lebih lama dibandingkan dengan pengobatan secara farmakologi. Hal ini disebabkan karena senyawa-senyawa yang terkandung dalam obat non farmakologi tersebut membutuhkan waktu untuk menyatu dalam metabolisme tubuh. Sedangkan pengobatan secara farmakologi bekerja dengan cara meredam gejala penyakit.

Lambatnya penurunan kadar asam urat yang dialami penderita gout juga dipengaruhi oleh beberapa faktor, selain karena lambatnya kerja obat non farmakologi, hal ini juga dipengaruhi oleh diet makanan yang tidak seimbang. Meskipun diet sudah kontrol tetapi tidak dipantau secara maksimal. Diperkuat dengan teori Utami (2009) menegaskan bahwa peningkatan kadar asam urat umumnya disebabkan karena pola makan yang tidak seimbang.

Selama penelitian pemberian air rebusan daun alpukat, tidak ditemui efek samping yang dapat mengganggu kenyaman maupun merugikan penderita gout yang mengkonsumsi air rebusan daun alpukat tersebut. Oleh sebab itu, untuk penderita gout akut, dapat menggunakan air rebusan daun alpukat sebagai terapi non farmakologi dengan dosis yang tepat tanpa pengobatan secara farmakologi untuk mempercepat proses penyembuhan, dimana menurut teori yang dikembangkan oleh Misdiarly (2007) gout akut dapat pulih tanpa pengobatan, tetapi memakan waktu selama 10-14 hari. Selanjutnya penderita gout kronis dapat menggunakan air rebusan daun alpukat sebagai terpi komplementer.

Kadar asam asam urat juga dapat diminimalisir dengan cara memodifikasi gaya hidup dengan cara membatasi asupan makanan yang mengandung tinggi purin dan membiasakan minum air putih 2 liter sehari untuk menjaga kesehatan ginjal.

Responden diharapkan dapat mencegah peningkatan kadar asam urat darah dengan obat alternative menggunakan obat tradisional salah satunya meminum rebusan daun alpukat karena adanya pengaruh rebusan daun alpukat terhadap penurunan kadar asam urat darah pada penderita gout. 


\section{KESIMPULAN}

Beberapa hal yang dapat disimpulkan dalam penelitian ini adalah :

1. Kadar asam urat darah pada kelompok kontrol dan kelompok perlakuan sebelum diberikan rebusan daun alpukat pada penderita gout di Klinik Pratama Barokah Kabupaten Sumenep nilai rata-rata kelompok kontrol 8,54 $\mathrm{mg} / \mathrm{dl}$ dan kelompok perlakuan 7,5 mg/dl.

2. Kadar asam urat darah pada kelompok kontrol dan kelompok perlakuan sesudah diberikan rebusan daun alpukat pada penderita gout di Klinik Pratama Barokah Kabupaten Sumenep nilai rata-rata pada kelompok kontrol $8,62 \mathrm{mg} / \mathrm{dl}$ dan kelompok perlakuan $6,5 \mathrm{mg} / \mathrm{dl}$.

3. Ada perbedaan yang signifikan terhadap penurunan kadar asam urat darah pada penderita gout di Klinik Pratama Barokah Kabupaten Sumenep pada kelompok kontrol dan perlakuan sesudah diberikan rebusan daun alpukat.

\section{DAFTAR PUSTAKA}

Afin, T., \& Friends. (2013). Daun Dahsyat. (N. Hidayah, Ed.) (pertama). Jogjakarta: KATAHATI.

Andareto, O. (2015). Apotik Herbal di Sekitar Anda. (R. D. Aryanti, Ed.) (Pertama). Jakarta: PUSTAKA ILMU SEMESTA.

Artini, N. P. R., Wahjuni, S., \& Sulihingtyas, W. D. (2012). EKSTRAK DAUN SIRSAK (Annona muricata L.) SEBAGAI ANTIOKSIDAN PADA PENURUNAN ASAM URAT TIKUS WISTAR, 127-137.

Bardan, S. N. (2007). Tanaman Berkhasiat Obat. (A. D. Rufaida, Ed.). Jakarta: PT Sunda Kelapa Pustaka.

Dalimartha, S. (2011). Resep Tumbuhan Obat untuk Obat Asam Urat. Jakarta: Penebar Swadaya.

Dalimartha, S., \& Dalimartha, F. A. (2014). Tumbuhan Sakti Atasi Asam Urat. (S. Nugroho, Ed.) (pertama). Jakarta: Penebar Swadaya.

Gusnedi, R. (2013). Analisis Nilai Absorbansi dalam Penentuan Kadar Flavonoid untuk Berbagai Jenis Daun Tanaman Obat. Pillar of Physics, 2, 76-83.

Hariana H. Arief. (2004). Tumbuhan Obat dan Khasiatnya (print book). Jakarta: Penebar Swadaya. 
Herliana, E. (2013). Penyakit Asam Urat Kandas Berkat Herbal. (D. Fahlevi, Ed.) (pertama). Jakarta: FMedia.

Kertia, N. (2009). Asam Urat. (I. Risdiyanto, Ed.) (2 ed.). Yogyakarta: B First.

Krisnatuti, D., Yenrina, R., \& Uripi, V. (1997). Perencanaan menu untuk penderita gangguan asam urat (Print Book). Jakarta: Penebar Swadaya.

Lingga, L. (2012). Bebas Penyakit Asam Urat Tanpa Obat. (I. Yunita, Ed.) (pertama). jakarta: PT AgroMedia Pustaka.

Mumpuni, Y., \& Wulandari, A. (2016). Cara Jitu Mengatasi Asam Urat. (Maya, Ed.) (1 ed.). Yogyakarta: Rapha Publishing.

Nursalam. (2014). Metodologi Penelitian Ilmu Keperawatan (4 ed.). Jakarta: Salemba Medika.

Permana, H. (2007). Tanaman Obat Tradisional (pertama). Bandung: TITIAN ILMU.

Pribadi, F. W., \& Ernawati, D. A. (2010). EFEK CATECHIN TERHADAP KADAR ASAM URAT , C - REACTIVE PROTEIN ( CRP ) DAN MALONDIALDEHID DARAH TIKUS PUTIH ( Rattus norvegicus ) HIPERURISEMIA, 4, 39-46.

Purwanto, D. (2011). GAMBARAN KADAR ASAM URAT PADA MAHASISWA ANGKATAN 2011 FAKULTAS KEDOKTERAN UNIVERSITAS SAM RATULANGI DENGAN INDEKS MASSA TUBUH $\geq 23 \mathrm{~kg} / \mathrm{m} 2$.

Savitri, D. (2017). Diam-Diam Mematikan, Cegah Asam Urat dan Hipertensi. (S. Adams, Ed.) (1 ed.). Yogyakarta: HEALTHY.

Setiadi. (2013). Konsep dan Praktik Penulisan Riset Keperawatan (kedua). Yogyakarta: Graha Ilmu.

Sintiawati, E., \& Yuswantina, R. (2013). Efek Pemberian Perasan Buah Strawberry (Fragaria virginiana Mil) Terhadap Penurunan Kadar Asam Urat Tikus Putih Jantan Galur Wistar, 0-6. 
Siswadi. (2006). Budidaya Tanaman Obat. (Sumarni, Ed.) (Pertama). Yogyakarta: PT Citra Aji Parama.

Soenanto, H. (2009). 100 Resep Sembuhan Hipertensi, Asam Urat, Obesitas. Jakarta: PT Elex Media Komputindo.

Soeroso, J., \& Algristian, H. (2011). Asam Urat. (Y. Destarina, Ed.) (1 ed.). Jakarta: Penebar Plus.

Sustrani, L., Alam, S., \& Hadibroto, I. (2007). Asam Urat. (A. D. Maksudi, Ed.) (kelima). Jakarta: PT Gramedia Pustaka Utama.

Ulung, G. (2014). Sehat Alami dengan Herbal (Print Book). Jakarta: PT Gramedia Pustaka Utama.

Utami, P., \& Tim, L. (2003). Tanaman Obat untuk Mengatasi Rematik \& Asam Urat. (Y. Tetty, Ed.) (Pertama). Jakarta: PT AgroMedia Pustaka.

Widiarti, T. (2010). Mengenal Tanaman dan Khasiatnya. Surabaya: ARKOLA 